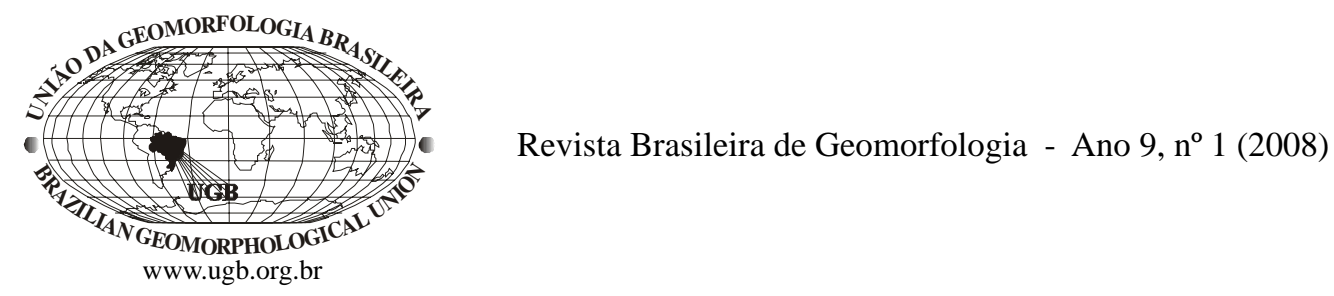

\title{
GEOLOGIA E GEOMORFOLOGIA DA PLANÍCIE ALUVIAL DO RIO IVAÍ EM SEU CURSO INFERIOR
}

\author{
Manoel Luiz dos Santos \\ Universidade Estadual de Maringá-DGE/GEMA \\ Av Colombo 5790, CEP 87020-900, Maringá-PR
}

José Candido Stevaux

Universidade de Guarulhos, Guarulhos - SP mldsantos@uem.br

Nelson Vicente Lovatto Gasparetto

Universidade Estadual de Maringá-DGE/GEMA Av Colombo 5790, CEP 87020-900, Maringá-PR

Edvard E. de Souza Filho

Universidade Estadual de Maringá-DGE/GEMA Av Colombo 5790, CEP 87020-900, Maringá-PR

\section{Resumo}

O rio Ivaí exerce importante papel para o estado do Paraná. Sua bacia hidrográfica abrange uma área de $35.845 \mathrm{~km}^{2}$, sendo 70\% dessa área situada na região noroeste do estado. Ao longo dos $685 \mathrm{~km}$ do seu curso, drena as litologias Eo-Paleozóicas e Mesozóicas da bacia sedimentar do Paraná. O rio Ivaí desenvolve uma planície aluvial somente em seu curso inferior. Essa se estende desde sua foz no rio Paraná, no município de Icaraíma - PR, até cerca de 150km a montante, na corredeira do Ferro, município de Tapira - PR. Nessa região, de baixas declividades, o rio apresenta um padrão meândrico bastante encaixado e com um forte controle estrutural e litológico. O mapeamento geológico e geomorfológico, baseado em interpretação de imagens, em testemunhos de sondagem e em descrições de afloramento, permitiu dividir a planície em seis unidades morfoestratigráfias: Planície Paraná-Ivaí, Planície Ivaí, Terraço Paraná, Terraço Ivaí, Leque Aluvial e Canal Fluvial. As características morfológicas, estruturais e sedimentares de cada uma dessas unidades são discutidas nesse trabalho. O posicionamento estratigráfico das diferentes unidades possibilita um panorama da arquitetura e evolução da planície aluvial.

Palavras-chave: Rio Ivaí, planície aluvial, evolução

\begin{abstract}
With a basin area of 35,845 $\mathrm{km}^{2}$ and $685 \mathrm{~km}$ long the Ivai River is an important drainage basin of the Paraná State and runs over Eo-Paleozoic and Mesozoic rocks of Paraná Sedimentary Basin. In the most its channel runs over rock becoming an alluvial river only in its lower course at $150 \mathrm{~km}$ from the mouth in the Paraná River at Icaraíma Town (PR). In this area river has an incased meandering channel under structural and lithological control.

The geological and geomorphological maps of the area present six morphostratigraphic unities studied in this paper: ParanáIvai Plain, Ivai Plain, Paraná Terrace, Ivai Terrace, Alluvial Fan and Flvuail Channel. The facies analysis and stratigraphic correlation it was possible to present an overview of deposits architectural and evolution of the alluvial plain.
\end{abstract}

Keywords: Ivai river, alluvial plain, evolution 


\section{Introdução}

O crescente uso dos recursos hídricos para fins agrícolas, industriais, de abastecimento e saneamento, de geração de energia, de transporte ou mesmo para a recreação coloca em evidência os aspectos do meio físico dos sistemas fluviais. Nesse sentido, o entendimento da geomorfologia fluvial é estratégico, pois viabiliza a exploração sustentada dos recursos naturais para os diversos setores da atividade humana.

Para o rio Ivaí, os estudos geomorfológicos são quase inexistentes, destacando-se o relatório da COPEL (1984), os estudos sobre perdas de solo (Santos, 1999), clima (Andrade, 2002), regime de débito (Ramos, 1973; Destefani, 2005) e finalmente, acerca da hidrodinâmica do canal, os estudos de Barros (2006), Biazin (2005) e de Kuerten (2006).

O rio Ivaí em seu curso inferior apresenta uma diversidade de depósitos sedimentares gerados em contextos geomorfológicos diferentes dentro da planície aluvial. Cada sub-ambiente (canal, planície proximal ou planície distal) do sistema deposicional pode ser identificado por sua morfologia, geometria dos depósitos e por uma associação faciológica decorrentes dos processos geomórficos e sedimentares atuantes durante sua formação. A íntima relação entre as fácies sedimentares e a morfologia dos sistemas fluviais levou a construção de modelos sedimentares verticais, que ganharam forte impulso a partir do desenvolvimento e imediata aceitação do modelo para rios meandrantes proposto por Allen (1983).

Uma aparente evolução aos modelos verticais é representada pela análise tridimensional das associações faciológicas, buscando a arquitetura dos depósitos a partir de suas geometrias internas e externas (Allen, 1983; Friend, 1983; Ethridge et al, 1987; Muños et al, 1992). Miall (1992), propõe a análise de elementos arquitetônicos para o sistema fluvial, sugerindo oito tipos básicos. As associações entre esses elementos gerariam os diferentes estilos fluviais encontrados na natureza.

Brierley (1991) analisando a sedimentação do rio Squamish (Canadá), utiliza o termo unidade morfoestratigráfica - "unidade deposicional definida por sua geometria tridimensional associada com suas características sedimentares". Esse conceito tem uma grande importância para a geomorfologia fluvial, pois alia a forma do depósito e a sua posição espaço temporal com suas características sedimentares.

O presente trabalho procurará integrar os aspectos sedimentológicos com as características geomorfológicas dos depósitos da planície aluvial do rio Ivaí, adaptando para a situação local os conceitos de unidade morfoestratigráfica. A área desse trabalho está localizada no curso inferior do rio Ivaí entre os municípios paranaenses de Tapira e Icaraíma (Pontal do Tigre), Figura 1.

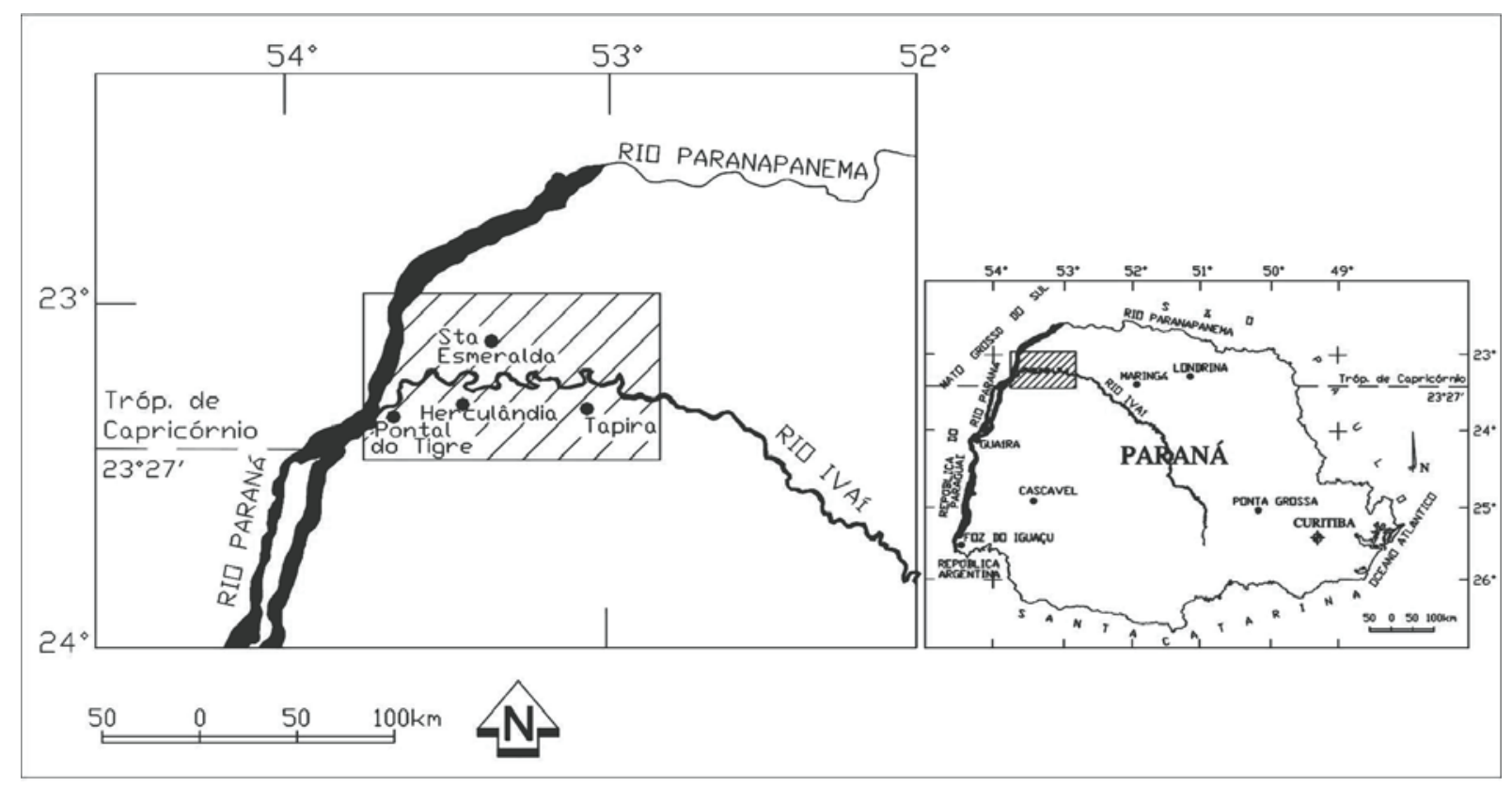

Figura 1 - Mapa de localização da área de estudo 


\section{Materiais e métodos}

Para o mapeamento das unidades morfoestratigráficas, ocorrentes na planície aluvial do rio Ivaí, foram utilizadas técnicas clássicas do mapeamento em geomorfologia fluvial. A interpretação de imagens de sensoriamento remoto (fotografias aéreas 1:25.000 e 1:70.000 e imagens de satélite) foram acompanhadas de trabalhos de campo. Foram feitos 10 furos de sondagem à vibração, nas diferentes unidades mapeadas e, nessas foram descritas as fácies sedimentares e suas associações. Os depósitos ocorrentes nas margens do canal fluvial foram descritos e amostrados. No canal fluvial foram levantadas três seções transversais: a montante no médio setor e a jusante da planície aluvial, junto à foz do rio Ivaí. Nessas seções foram medidas as velocidades de corrente, a geometria do canal e as vazões no momento da coleta. Para tal, foram usados o molinete fluviométrico, o ecobatímetro acoplado a um sistema de georreferenciamento (GPS) e um perfilador acústico de corrente - Austic Dopler Current Profile (ADCP). Nas seções transversais também foram amostradas, e analisadas em laboratório, as cargas de fundo e de suspensão hidrotransportada. Duas datações ${ }^{14} \mathrm{C}$ foram efetuadas nos depósitos do sistema aluvial. Estas, a despeito do reduzido número, permitiram um posicionamento cronoestratigráfico dos depósitos amostrados. O reduzido número de datação se deve a dificuldade de se encontrar material orgânico para a análise ${ }^{14} \mathrm{C}$, devido à rápida degradação da matéria orgânica em climas tropicais.

\section{A planície aluvial do rio Ivaí}

O rio Ivaí nasce na região da serra da Esperança (sudeste do Paraná), da junção de dois rios: rio dos Patos, que nasce no município de Inácio Martins e rio São João (Prudentópolis-PR). Esses se unem nas proximidades da cidade de Ivaí - PR, onde a partir da confluência, recebe seu nome. O seu escoamento geral se efetua em direção ao noroeste do estado, até a foz, no rio Paraná, em Pontal do Tigre (Icaraíma - PR), com um percurso total de 685km.

O rio Ivaí somente apresenta uma planície aluvial nos seus últimos $150 \mathrm{~km}$, a partir da corredeira do Ferro, em Tapira-PR (Fig. 2). A planície aluvial representa um conjunto de depósitos com mais de $20 \mathrm{~m}$ de espessura, dominantemente formado por pelitos, subordinadamente de areia fina e com delgadas e descontínuas camadas de cascalho e areia grossa depositadas sobre a Formação Caiuá. Essa formação aflora somente em alguns pontos na margem ou no leito do rio, como um arenito fino a médio, estratificado (Fácies Sp), de coloração avermelhada e fortemente cimentado. $\mathrm{O}$ alto grau de cimentação dessa formação na região da planície exerce um forte controle litológico no canal do rio Ivaí, que, aliado aos lineamentos tectônicos, condiciona seu traçado.

Na região centro-sul brasileira os grandes alinhamentos tectônicos de direção NW, NE e EW, desenvolvidos desde o final do Mesozóico, são bastante reconhecidos na literatura (Asmuz, 1981; Soares et al, 1982; Amaral e Costa, 1983; Zalán et al, 1986). Esses lineamentos regionais influenciaram

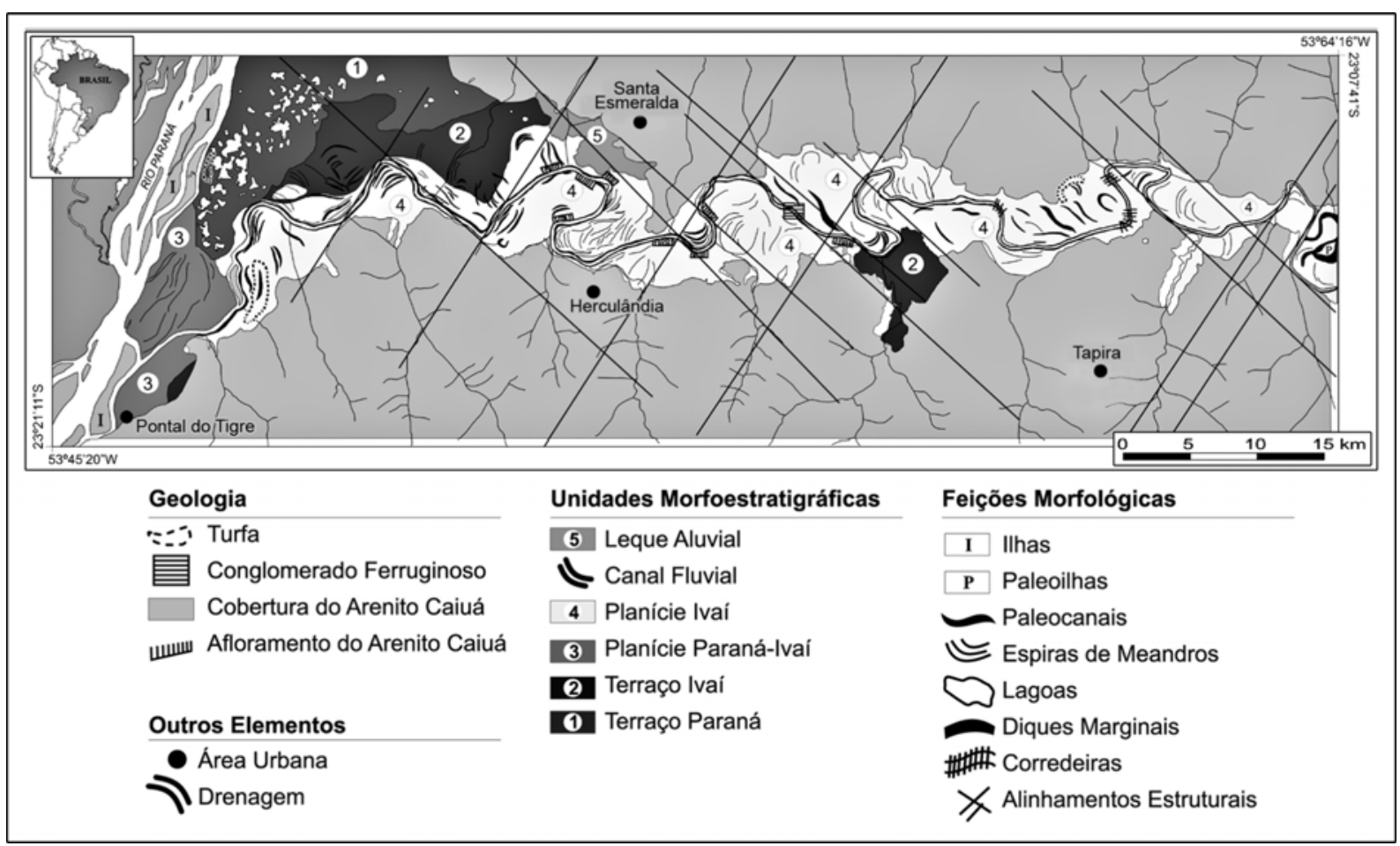

Figura 2 - Mapa geológico-geomorfológico da planície do rio Ivaí. Modificado de Santos (2004) e Aguiar e Santos (2004) 
na sedimentação do Grupo Bauru, como mostram os trabalhos de Fulfaro (1974), Fulfaro et al (1982), Fulfaro e Barcelos (1992), Jabur (1992) e Fernandes (1992). Estruturas tipo "rift" de direção NNE, geradas por falhamentos distensivos, no setor norte da bacia sedimentar do Paraná, permitiram a acumulação das maiores espessuras de basalto (Molina et al, 1989). A manutenção do caráter subsidente dessa faixa propiciou o acúmulo dos sedimentos cretáceos suprabasálticos (Fernandes, 1992). O mapa de isópacas da Formação Caiuá mostra duas sub-bacias alinhadas NE-SW isoladas por um alto estrutural no Pontal de Paranapanema, que separa os dois depocentros com uma súbita interrupção ao sul da bacia pelo lineamento estrutural do rio Piquiri (Saad et al, 1988 e Jabur, 1992).

O curso do rio Paraná desenvolve-se na direção NESW. No setor entre a foz do rio Piquiri e o Pontal do Paranapanema, a calha do rio ocupa uma posição centralizada em relação à bacia deposicional do Caiuá, coincidindo com sua direção. Vários lineamentos estruturais cortam transversalmente a bacia hidrográfica superior do rio Paraná, na direção NW e EW. Esses lineamentos são bastante reconhecidos e recebem as denominações de: alinhamento Guapiara, alinhamento rio Alonzo, alinhamento São Gerônimo-Curiúva, alinhamento do rio Paranapanema e alinhamento do rio Tietê, tendo sido descritos por Fulfaro (1974), Ferreira (1982) e Fulfaro et al (1982).

O rio Ivaí na região de sua planície aluvial se insere nesse contexto; os alinhamentos tectônicos a NW e NE con- trolam o traçado meândrico do rio. Esses alinhamentos são reconhecidos nas direções de fratura dos afloramentos do Arenito Caiuá dentro do canal do rio. O rio Ivaí abandona o sentido geral NW e passa a correr no sentido E-W a partir da corredeira do Ferro (Tapira) até sua foz, no rio Paraná. Essa direção também é encontrada em outros rios do estado, como o Tibagí e o Paranapanema.

A planície aluvial desenvolve-se simetricamente em relação ao canal e, lateralmente ao canal, ocorrem diques marginais contínuos, com até $5 \mathrm{~m}$ acima do nível da planície. A largura da planície aluvial é maior próximo à sua foz no rio Paraná, exibindo cerca de $15 \mathrm{~km}$, e sendo nessa área, construída pela dinâmica conjunta desses dois rios. Em direção a montante, a planície diminui sensivelmente sua largura, variando de $3 \mathrm{~km}$ a $5 \mathrm{~km}$ no início da planície aluvial, no município de Tapira, distante cerca de $150 \mathrm{~km}$ a montante da foz. Por outro lado, a declividade do canal diminui para jusante, de $8,0 \mathrm{~cm} / \mathrm{km}$ no trecho superior da planície aluvial para $4,2 \mathrm{~cm} / \mathrm{km}$ no seu trecho inferior.

A geomorfologia da planície aluvial pode ser dividida em seis unidades morfoestratigráficas de idades distintas: Planície Paraná-Ivaí, Planície Ivaí, Terraço Paraná, Terraço Ivaí, Leque Aluvial e Canal Fluvial (Fig. 2). Todas as unidades ocorrem em diferentes cotas em relação ao canal fluvial. As características morfológicas e sedimentares de cada unidade estão sumarizadas na Quadro 1.

Quadro 1 - Características das unidades morfoestratigráficas da planície aluvial do rio Ivaí no seu curso inferior

\begin{tabular}{|c|c|c|c|c|c|c}
\hline Unidades & Cotas & Largura & Morfologia & $\begin{array}{c}\text { Depósitos/ } \\
\text { Fácies }\end{array}$ & $\begin{array}{c}\text { Feiçóes } \\
\text { morfológicas }\end{array}$ & $\begin{array}{c}\text { Limites/ } \\
\text { contatos }\end{array}$ \\
\hline $\begin{array}{c}\text { Planície } \\
\text { Paraná/Ivaí }\end{array}$ & $\begin{array}{c}231 \mathrm{a} \\
235\end{array}$ & $15 \mathrm{Km}$ & Plana & $\begin{array}{c}\text { Argila, argila } \\
\text { com MO* } \\
\text { areias }\end{array}$ & $\begin{array}{c}\text { Paleocanais, } \\
\text { diques marginais, } \\
\text { pântanos }\end{array}$ & Evidente \\
\hline $\begin{array}{c}\text { Terraço } \\
\text { Paraná }\end{array}$ & $\begin{array}{c}236 \mathrm{a} \\
24 \mathrm{l}\end{array}$ & $9 \mathrm{Km}$ & Plana & $\begin{array}{c}\text { Areia fina a } \\
\text { média, cascalho } \\
\text { com matriz } \\
\text { arenosa, turfas }\end{array}$ & Lagoas & Evidente \\
\hline $\begin{array}{c}\text { Terraço } \\
\text { Ivai }\end{array}$ & $\begin{array}{c}239 \mathrm{a} \\
247\end{array}$ & $\begin{array}{c}2 \mathrm{Km} \text { a } \\
7 \mathrm{Km}\end{array}$ & $\begin{array}{c}\text { escalonados } \\
\text { planos a } \\
\text { pouco } \\
\text { ondulados }\end{array}$ & $\begin{array}{c}\text { Pelitos, areia fina } \\
\text { maciça e com } \\
\text { MO* }\end{array}$ & $\begin{array}{c}\text { Paleocanais, } \\
\text { paleoilhas }\end{array}$ & Evidente \\
\hline $\begin{array}{c}\text { Planície } \\
\text { Ivai }\end{array}$ & $\begin{array}{c}235 \mathrm{a} \\
250\end{array}$ & $\begin{array}{c}\text { Variável } \\
\text { até } 13 \mathrm{Km}\end{array}$ & $\begin{array}{c}\text { Plana com } \\
\text { inclinação } \\
\text { para o rio }\end{array}$ & $\begin{array}{c}\text { Pelitos, areias e } \\
\text { cascalhos }\end{array}$ & $\begin{array}{c}\text { Paleocanais, } \\
\text { espiras de } \\
\text { meandros, diques } \\
\text { marginais e turfas }\end{array}$ & Evidente \\
\hline $\begin{array}{c}\text { Leques } \\
\text { aluviais }\end{array}$ & $\begin{array}{c}246 \mathrm{a} \\
291\end{array}$ & $2 \mathrm{Km}$ & $\begin{array}{c}\text { Lobada } \\
\text { inclinada } \\
\text { para o rio }\end{array}$ & $\begin{array}{c}\text { Areia fina maciça } \\
\text { Leques }\end{array}$ & Evidente \\
\hline $\begin{array}{c}\text { Canal } \\
\text { fluvial }\end{array}$ & $\begin{array}{c}220 \mathrm{a} \\
235\end{array}$ & $\begin{array}{c}150 \mathrm{~m} \text { a } \\
250 \mathrm{~m}\end{array}$ & $\begin{array}{c}\text { Meândrico } \\
\text { encaixado }\end{array}$ & $\begin{array}{c}\text { Pelitos, areias e } \\
\text { cascalhos }\end{array}$ & $\begin{array}{c}\text { Corredeiras, } \\
\text { barras e ilhas }\end{array}$ & Evidente \\
\hline
\end{tabular}

*MO = matéria orgânica 


\section{Unidade Planície Paraná-Ivaí}

Desenvolve-se junto à região da foz do rio Ivaí e representa a região dominada pela dinâmica conjunta dos rios Paraná e Ivaí. Em toda a planície aluvial, essa é a única unidade que se constitui em uma planície de inundação ativa. É uma região plana disposta simetricamente ao canal do rio Ivaí, com cerca de $15 \mathrm{~km}$ de largura entre as cotas 231 a 235. Essa unidade é dominantemente formada por depósitos de argila e subordinadamente areia fina. É cortada por paleocanais do rio Ivaí, que por abandono permitiram a deposição de espessos depósitos de argila maciça rica em matéria orgânica (fácies Fm de
Miall, 1978). Nessa unidade os diques marginais somente se desenvolveram ao longo da margem esquerda do rio Ivaí. Atrás dos diques, no lado esquerdo do canal, nas partes mais distais da planície, ocorrem pântanos e alagadiços que ocupam as regiões mais deprimidas da planície. O contato dessa unidade com as outras unidades é bem marcado e facilmente reconhecível. Ao sul, o contato com a unidade Terraço Ivaí, mais elevada mostra uma superfície erosiva com cerca de 3m de desnível. Ao norte, o contato da planície com a unidade Terraço Paraná é mais marcado e exibe uma superfície erosiva de cerca de $8 \mathrm{~m}$ de altura (Fig. 3).

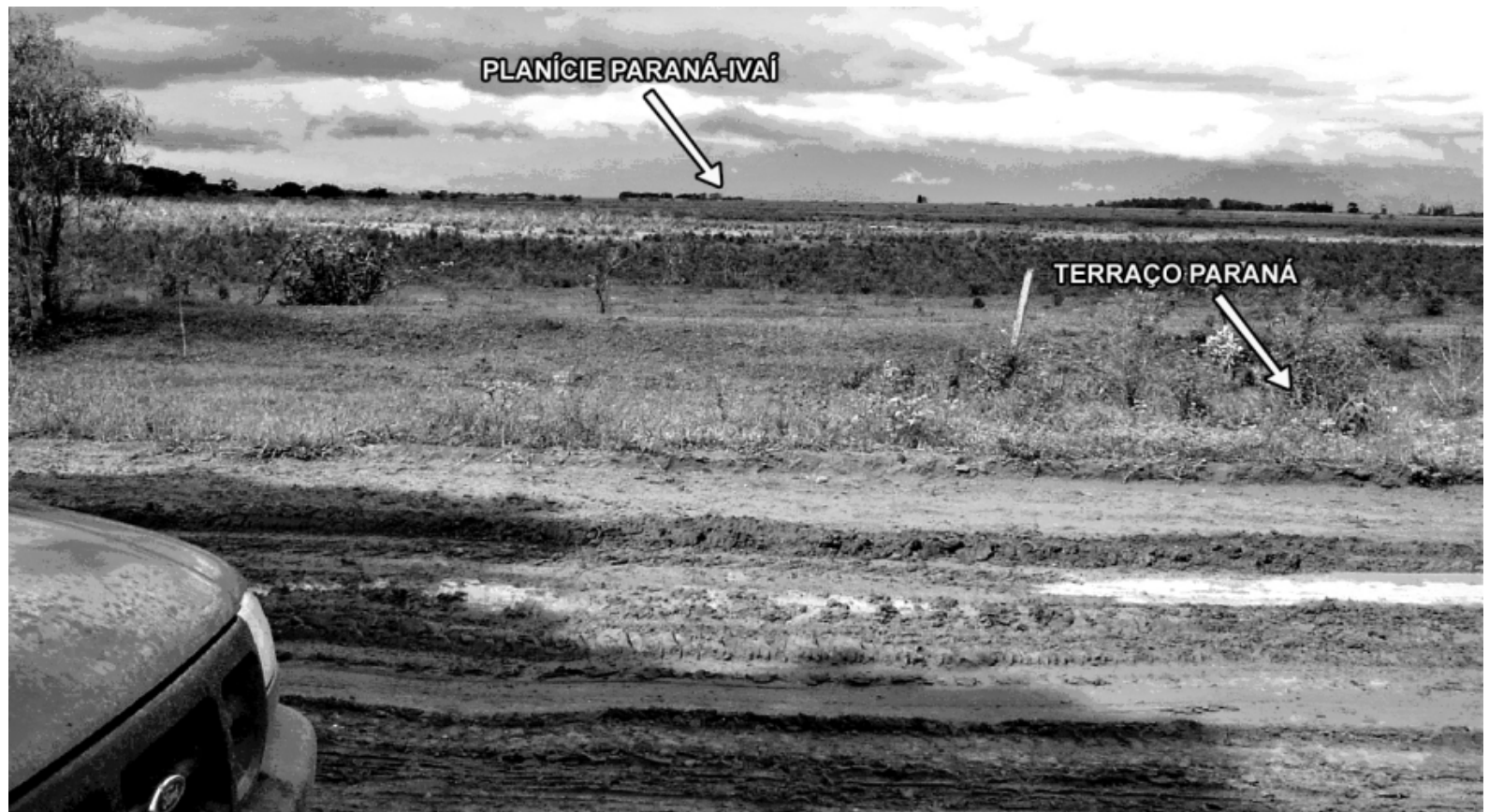

Figura 3 - Fotografia mostrando o relevo da planície Paraná/Ivaí no município de Querência do Norte-PR. A parte superior da foto mostra o desnível entre a unidade da planície Paraná-Ivaí com o Terraço Paraná

\section{Unidade Terraço Paraná}

Ocorre ao norte da área de estudo, ladeando o canal do rio Paraná. Essa unidade é formada por depósitos dominantemente de areia fina a média maciça (Fácies Sm), tendo sua origem associada à dinâmica sedimentar do rio Paraná. Na base dessa unidade, em contato discordante com o arenito da Formação Caiuá, ocorrem cascalhos polimíticos com matriz arenosa, com seixos de calcedônia, arenito e sílex imbricados (Fácies Gms).

Essa unidade tem como característica a ocorrência de inúmeras lagoas, circulares, semicirculares e amebóides, com dezenas a centenas de metros de diâmetro (Fig. 4). Na parte mais proximal ao rio Paraná ocorrem depósitos de turfa, e turfa fibrosa com espessura que varia de $40 \mathrm{~cm}$ a $150 \mathrm{~cm}$, tendo na base dos depósitos a ocorrência de areia fina rica em matéria orgânica (Fácies So). Esses depósitos orgânicos se desenvolveram nas depressões formadas pelas lagoas (Fig. 5).

As características texturais e geomorfológicas desse terraço permitem correlacioná-lo com a unidade Taquaruçu (terraço colúvio-aluvial) de Justus (1985), Stevaux (1993 e 1994). A unidade Taquaruçu ocorre paralelamente ao rio Paraná no estado de Mato Grosso do Sul, entre as cotas 250m e 280m, portanto mais elevada que o Terraço Paraná cujas cotas altimétricas encontram-se entre $236 \mathrm{~m}$ e $241 \mathrm{~m}$. Isso se deve a processos neotectônicos que tornam essa área do lado esquerdo do rio Paraná mais rebaixada do que a que se desenvolve na margem oposta.

Os processos neotectônicos acompanham todo o desenvolvimento da planície aluvial do rio Paraná (Stevaux 1994, Santos, 1997, Souza Filho e Fortes et al, 2005). Na região desse estudo, esses processos foram descritos por Sou- 
za Filho (1993). A análise da distribuição da unidade Taquaruçu, em todo o alto rio Paraná, contribuiu para que Souza Filho (1993) e Souza Filho e Stevaux (1997) definissem o movimento relativo dos diversos blocos estruturais delimitados pelas estruturas que ocorrem ao longo do rio Paraná e de seus afluentes, visto que tais ocorrências variam de altitude de um lado para outro dos principais rios.

\section{Unidade Terraço Ivaí}

Os terraços associados aos depósitos do rio Ivaí na região de sua foz estão compreendidos entre as cotas 239m e $244 \mathrm{~m}$. Esses terraços apresentam morfologia levemente ondulada com desnível de cerca de $3 \mathrm{~m}$ a $4 \mathrm{~m}$ acima da planície do rio Ivaí. São formas descontínuas ocorrendo em duas regiões: a primeira na parte jusante da planície aluvial, em Pontal do Tigre (Icaraíma) e a segunda no trecho médio da planície aluvial, no município de Querência do Norte.

No trecho mais a jusante, na região de Pontal do Tigre, na margem esquerda do rio Ivaí, essa unidade ocupa uma pequena área disposta entre a planície Paraná-Ivaí e os depósitos arenosos da cobertura superficial da Formação Caiuá. Forma um patamar escalonado quase plano, com mergulho muito suave em direção a calha do rio Ivaí, constituído por depósitos de areia fina maciça (Fácies Sm) e areia fina rica em matéria orgânica (Fácies Smo). A origem desse terraço está ligada tanto a processos aluviais relacionados ao rio Ivaí quanto aos coluviais relacionados à cobertura superficial do Arenito Caiuá.

Na margem direita do rio Ivaí, ainda na região da foz, no município de Querência do Norte, essa unidade é mais distribuída. Ocorre como uma área de cerca de $20 \mathrm{~km}$ de comprimento e largura variável de $2 \mathrm{~km}$ a $7 \mathrm{~km}$, disposta paralelamente ao longo do canal do rio. Forma um patamar escalonado, pouco ondulado, com declividade suave, que mergulha em direção ao rio Ivaí. Ao norte dessa unidade, o contato com o Terraço Paraná é abrupto e sinuoso, apresentando desnível de 4m (Fig. 4), enquanto ao sul essa unidade faz um contato menos nítido com a unidade Planície Ivaí.

Esse terraço aluvial é formado pela ocorrência conjunta de depósitos pelíticos, com quantidade variável de matéria orgânica (Fácies Fm, Fl) e de areia fina maciça ou estratificada (Fácies Sm, Smo, Sr e Sp). Um intricado conjunto de paleocanais e de espiras de meandro de direções variáveis mostra que esse depósito foi profundamente retrabalhado por processos de abandono de canal e de migração de meandros durante a evolução do rio Ivaí (Fig. 4). Em campo, a distinção do terraço com os depósitos da Planície do Ivaí é difícil, devido à semelhança entre os depósitos e ao retrabalhamento que o atual sistema e a atividade agrícola efetuam.

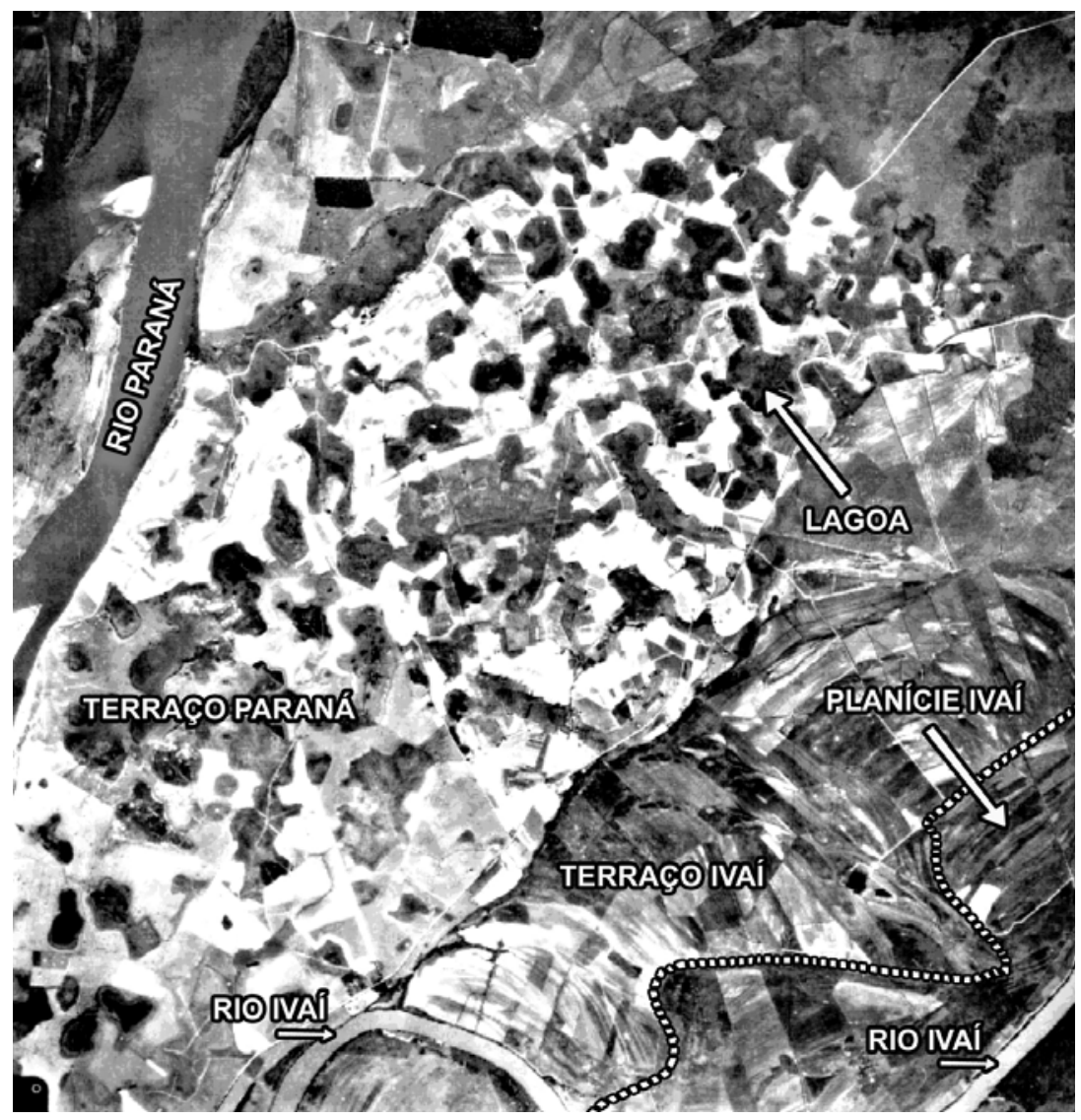

Figura 4 - Fotografia aérea mostrando o contato bem marcado entre as unidades Terraço Paraná e Terraço Ivaí. Observar no lado esquerdo da fotografia a ocorrência das lagoas que são características da primeira unidade. No Terraço Ivaí (lado direito da fotografia) tem a ocorrência de espiras de meandro orientadas grosseiramente perpendicular ao rio Ivaí. No canto inferior direito da fotografia, ladeando o canal do rio Ivaí, ocorre a unidade Planície Ivaí. Note que as espiras de meandro, nessa unidade, truncam as do Terraço Ivaí 
Porém, em fotografias aéreas, o conjunto de paleocanais e as espiras de meandro da planície do Ivaí corta discordantemente os paleocanais do Terraço Ivaí, atestando a idade mais nova da planície (Fig. 4). Nos baixios desenvolvidos pelos paleocanais e entre as espiras de meandro, a proximidade do lençol freático ou a forma- ção de alagados permitem a acumulação de matéria orgânica e o desenvolvimento de solos orgânicos e de turfas com grande quantidade de fibras, cujas espessuras variam de $30 \mathrm{~cm}$ a $60 \mathrm{~cm}$. Estas estão sobrepostas aos depósitos argilo-sitosos (Fácies Fm, Fl) desenvolvidos na fase de abandono dos canais.

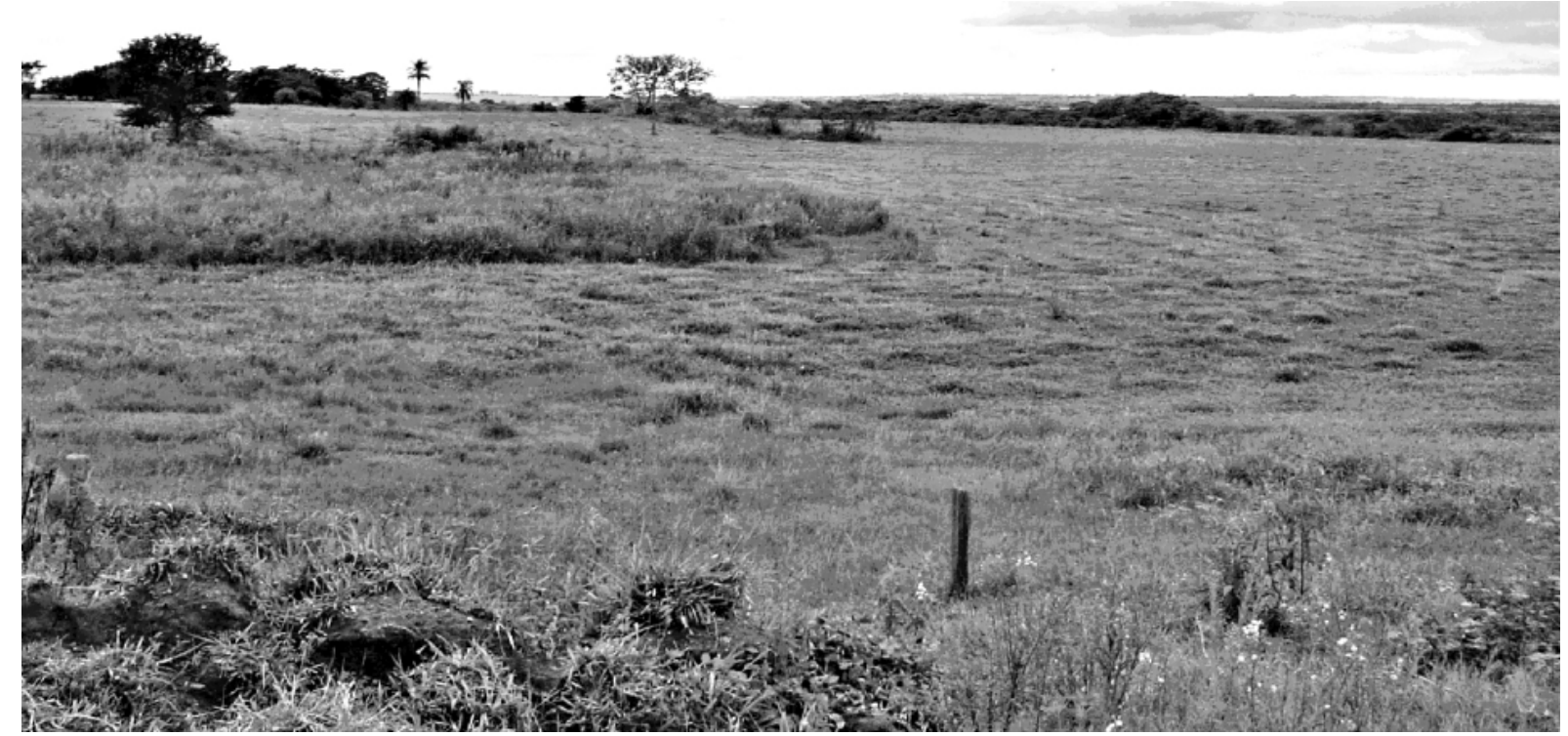

Figura 5 - Fotografia de uma lagoa seca na unidade Terraço Paraná, município de Querência do Norte - PR. A depressão formada pela lagoa permite a acumulação de matéria orgânica desenvolvendo solos orgânicos e turfas

\section{Unidade Planície do Ivaí}

Essa unidade desenvolve-se paralelamente ao canal do rio Ivaí constituída predominantemente por pelitos. Assentase em discordância sobre os arenitos da Formação Caiuá. Na base dos depósitos da planície, verifica-se a ocorrência de

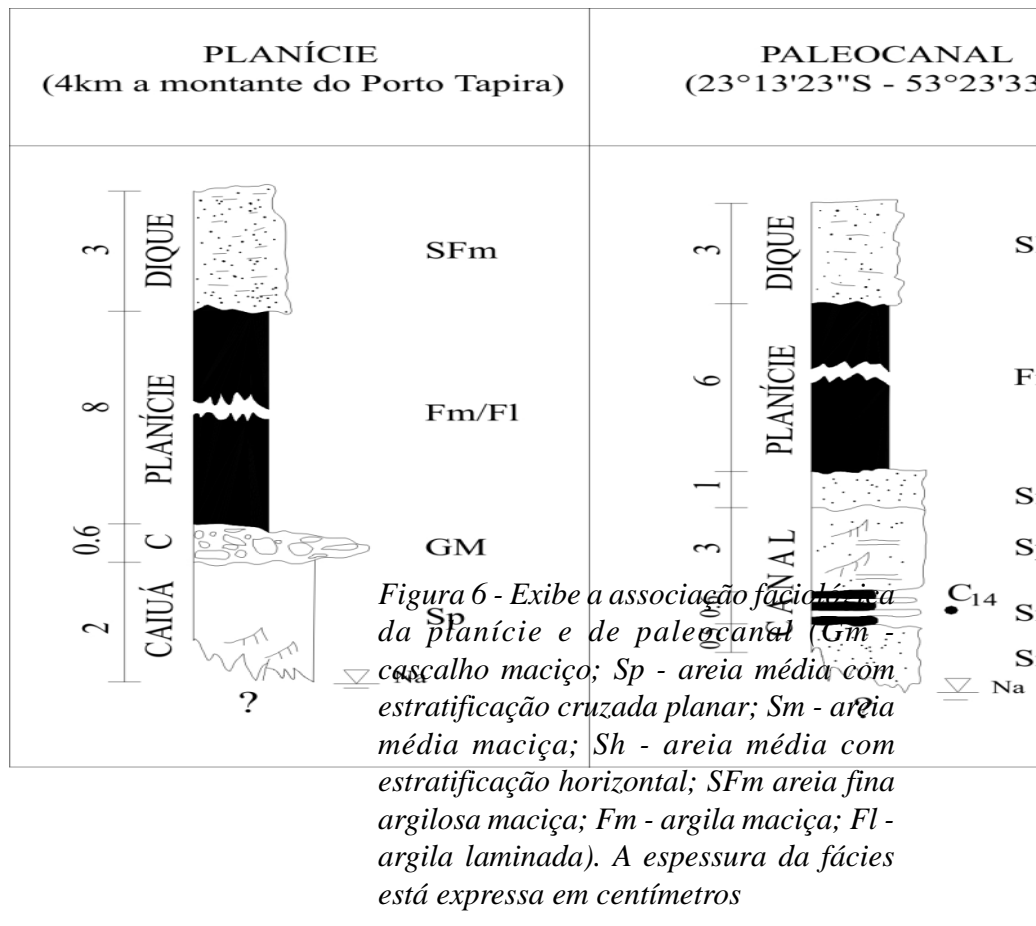


A planície do Ivaí mostra-se cortada por inúmeros paleocanais e espiras de meandro, cuja orientação geral nem sempre coincide com o traçado atual do canal. Os paleocanais da planície são de larguras variáveis, chegando até cerca de
$600 \mathrm{~m}$, e podem mostrar paleoilhas preservadas dentro de seu antigo curso (Fig. 7). Muitas vezes, esses paleocanais cortam a direção do curso atual e, nesse caso, permitem que se estude sua faciologia diretamente na margem do rio.

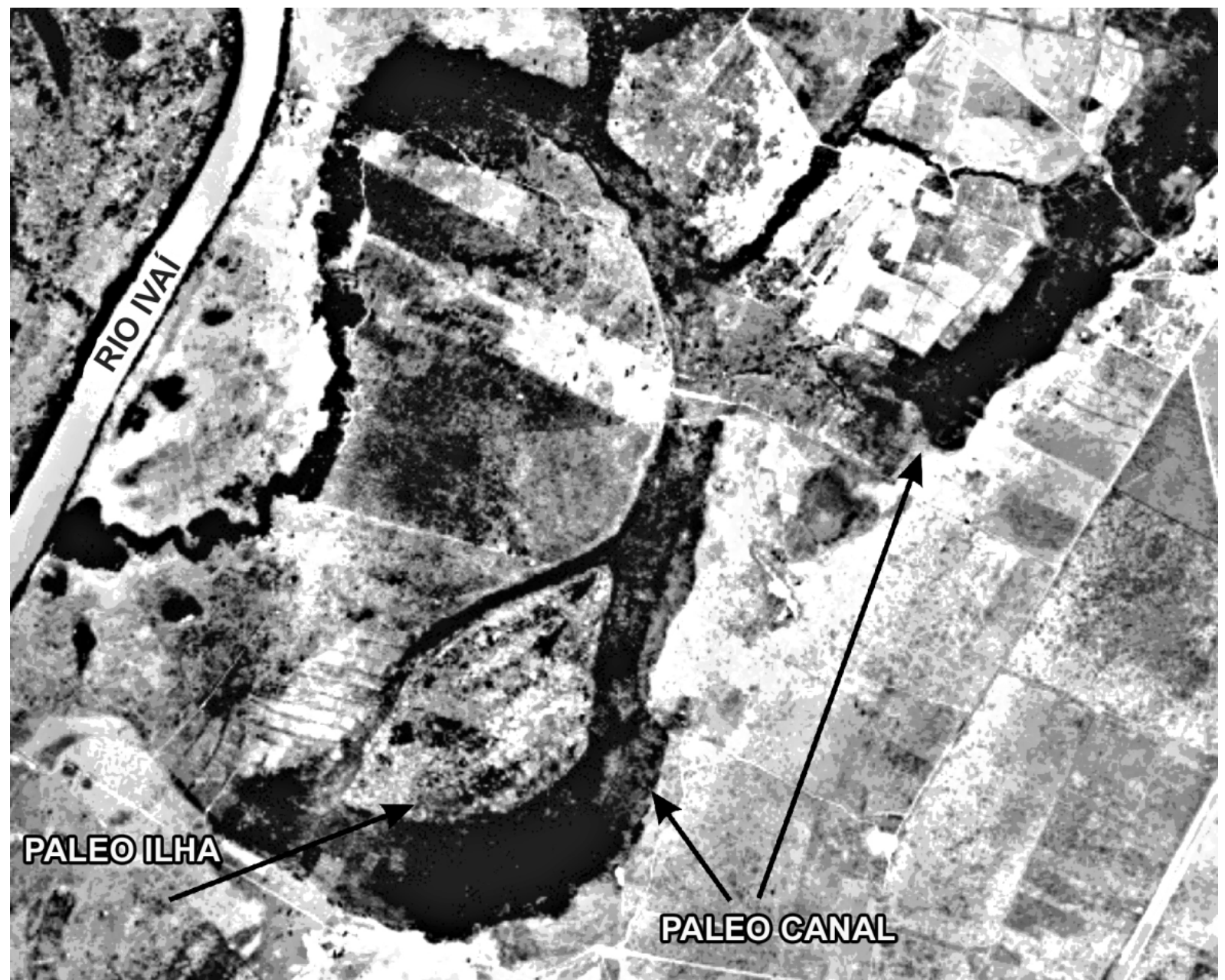

Figura 7 - Fotografia aérea da planície do rio Ivaí no município de Nordestina-PR, mostra a ocorrência de paleocanais com cerca de 400m de largura e de uma paleoilha. Note as espiras de meandro preservadas na superfície da paleoilha. Uma sondagem a vibração no paleocanal da parte inferior da fotografia, revelou um pacote de argila maciça (fácies Fm) com 11m de espessura. Escala aproximada: 1:30.000

Na região do Novo Porto Tapira, ocorre na margem direita do rio um paleocanal, que exibe uma sucessão faciológica com cerca $13 \mathrm{~m}$ de espessura, aflorante acima do nível do rio (Fig. 6). Na porção basal, ocorre um conjunto de fácies de areia fina a média com estratificação cruzada (Fácies Sp), microestratificação cruzada (Sr) e com estratificação horizontal (Fácies Sh), com cerca de $5 \mathrm{~m}$ de espessura. Segue-se a esse conjunto outro conjunto de fácies de argila maciça ou laminada (Fácies Fm, Fl), com cerca de $6 \mathrm{~m}$ de espessura. Essa associação faciológica indica uma nítida seqüência de abandono do paleocanal, com a energia do meio diminuindo para o topo do depósito. Uma análise de ${ }^{14} \mathrm{C}$ realizada em restos orgânicos na base aflorante desse depósito forneceu uma idade de $14.307 \pm 68$ anos A.P., indicando que esse paleocanal do rio Ivaí era ativo há pelo menos nessa idade. Sobre essa seqüência ocorrem depósitos de argila e areia fina relacionados ao dique marginal do canal atual, portanto, bem mais recentes que os depósitos sotopostos.

\section{Unidade Leque aluvial}

Essa unidade ocorre entre as cotas 291m a 246m, próximo a Santa Esmeralda, distrito de Querência do Norte (Fig. 2). Ocupa uma área de cerca de $10 \mathrm{~km}$ de comprimento e $2 \mathrm{~km}$ de largura média. Essa unidade depositou-se sobre a Planície do Ivaí, é formada pelo trabalho do córrego Santo Antônio e do ribeirão Água Furtada sobre os sedi- 
mentos arenosos, da cobertura superficial do Arenito Caiuá. O contato na parte proximal, com os depósitos da cobertura, é bem marcado por uma superfície erosiva. O contato distal, com a planície é gradativo, sendo observado apenas por uma pequena mudança na declividade do terreno, que se torna mais suave.

A declividade da superfície na região do leque está em torno de $15 \mathrm{~cm} / \mathrm{km}$ e cai para $3 \mathrm{~cm} / \mathrm{km}$ na região da Planície Ivaí, com o mergulho em direção ao rio. O leque aluvial é dominantemente formado por areia fina maciça de coloração mais clara que a da cobertura superficial, em razão da perda de argila e de óxidos de ferro.

Stevaux e Santos (1998) reconhecem a ocorrência de um leque colúvio-aluvial arenoso depositado sobre os sedimentos da planície do rio Paraná, na região de Porto Rico (PR) e sugerem sua formação no Holoceno Superior durante um breve período seco que experimentou essa região entre 2.000 e 3.000 anos A.P. A semelhança desse leque aluvial com aquele do rio Paraná, em relação a tipo de sedimento, situação topográfica, proximidade regional e situação estratigráfica, permite uma correlação entre essas duas unidades.

\section{Unidade Canal Fluvial}

O canal do rio Ivaí apresenta um padrão meândrico fortemente encaixado a montante da planície, e devido a isso, não apresenta nenhuma mobilidade lateral. O canal está entalhado desde a corredeira do Ferro (Tapira) até cerca de $20 \mathrm{~km}$ da foz no rio Paraná, sendo essa a região da planície com maior declividade $(8,2 \mathrm{~cm} / \mathrm{km})$. A altura das margens diminui para jusante, ao contrário da largura do canal, que aumenta para jusante, variando muito pouco de acordo com as variações do nível da água. Dentro do canal ocorrem poucas corredeiras, formadas por afloramentos do Arenito Caiuá dentro do leito do rio, ou por afloramentos de conglomerado fortemente limonitizados que se constituem na base do pacote sedimentar da planície.

No canal, as barras são pouco comuns e são formadas por seixos (Fig. 8) ou mais raramente por areia, sendo as últimas de dimensões muito reduzidas e dispostas lateralmente dentro do canal. As barras de seixos são bastante estáveis, e algumas, depois de colonizadas pela vegetação formam pequenas ilhas (Fig. 9). As barras de areia têm alta mobilidade dentro do canal, sendo facilmente destruídas nos níveis mais altos de água.

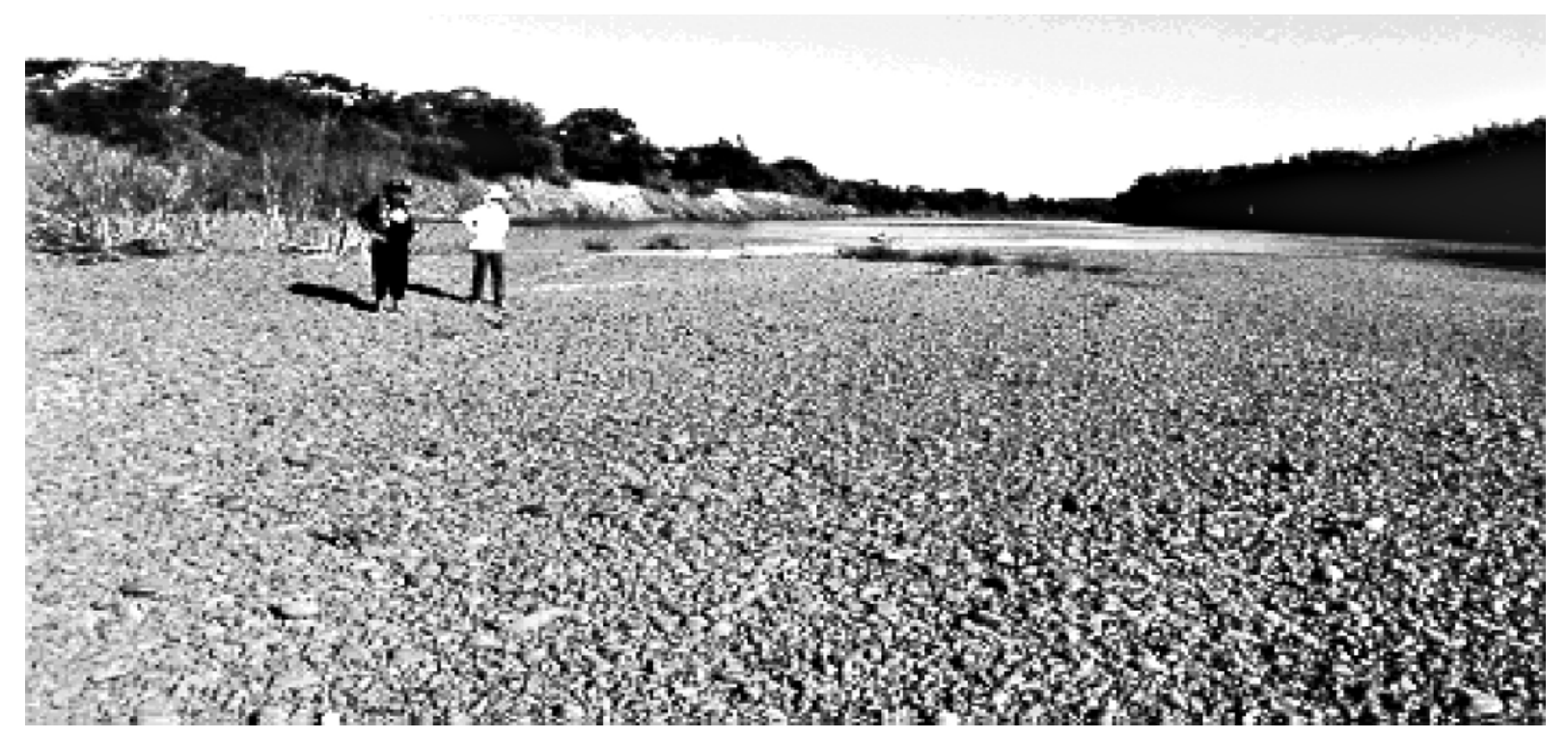

Figura 8 - Exibe uma barra formada por seixos no rio Ivaí, região de Herculândia. Os seixos estão imbricados segundo a direção do fluxo e apresentam uma composição variada, formam uma fácies clasto-suportada maciça $(\mathrm{Gm})$

Nas margens do canal, é comum a deposição de areia fina estratificada associada a argila maciça ou laminada, formando uma barra de cheia. Essas barras se desenvolvem devido ao forte entalhamento do canal, que em seus diferentes níveis acresce às margens, verticalmente, com material de fundo e suspensão por ele transportado. Freqüentemente, a distinção entre essa deposição atual sobre as margens e os depósitos mais antigos da planície é dificultada devido à ação da vegetação. Em Porto Tapira aflora na margem direita uma seqüência areno-pelítica com cerca de $12 \mathrm{~m}$ de altura acima do nível do rio. A datação de ${ }^{14} \mathrm{C}$, efetuada em restos vegetais coletados a 4,5m de altura, revelou uma idade menor que 200 anos A.P. (113,8 \pm 0.5\%M). Isso demonstra o forte trabalho vertical do rio dentro de sua calha e mostra a dificuldade de se separar depósitos modernos dos antigos, em regiões tropicais.

No município de Tapira, o leito do rio Ivaí apresenta certa simetria. O talvegue mostra um traçado retilíneo e está 
localizado próximo à margem direita do rio, onde se verifica a maior energia no fluxo. Nos sítios do canal próximo à sua margem esquerda ocorrem fluxos de menor intensidade, e são locais de acumulação de material mais fino. Nessa região, o canal do rio Ivaí tem largura média de 170m e profundidade média de $4 \mathrm{~m}$. O canal fluvial nos níveis médios de vazão ostenta margens com cerca de $15 \mathrm{~m}$ de altura acima do nível médio das águas. Lateralmente ao canal se desenvolvem diques marginais contínuos com cerca de $4 \mathrm{~m}$ de altura acima da planície. Sua constituição é areno-siltosa (Fácies Fm, Sr) e sobre eles se desenvolve vegetação arbórea de grande porte.

Em Pontal do Tigre (Icaraíma) se encontram as mais baixas declividades do canal $(4.2 \mathrm{~cm} / \mathrm{km})$, as seções transversais ao canal são aproximadamente simétricas e o talvegue mostra um traçado sinuoso. A largura média do canal é de cerca de 295m; portanto, é a seção da planície onde o rio Ivaí é mais largo. As margens mais baixas, a ausência de diques marginais na margem direita do canal e a interferência com a dinâmica do rio Paraná tornam esse setor da planície aluvial mais suscetível a inundações. Nesse caso, a situação é oposta à das seções a montante, onde o profundo encaixamento do canal e a ocorrência de altos diques marginais fazem com que a planície de inundação se comporte como um terraço, sujeito a inundações somente em cheias extremas. A profundidade média nessa seção é de 5,9m nos níveis médios de vazão.

O regime de débitos do rio Ivaí foi recentemente estudado por Destefani (2005), sendo caracterizado pela forte influência da precipitação e grande variação de nível. A descarga fluvial média na estação situada mais à jusante (Novo Porto Taquara) é de $727 \mathrm{~m}^{3} / \mathrm{s}$, mas a média das cheias é de $4.019 \mathrm{~m}^{3} / \mathrm{s}$, e a ocorrência de valores próximos ao da média são rara. Na maior parte do tempo (60\%), os valores são superiores a $1.000 \mathrm{~m}^{3} / \mathrm{s}$ ou próximos a $300 \mathrm{~m}^{3} / \mathrm{s}$ (37\% do tempo). O registro histórico da referida estação demonstra que os níveis fluviométricos variam entre $70 \mathrm{~cm}$ e $1.259 \mathrm{~cm}$, em uma seção em que o extravasamento do canal ocorre a $1.200 \mathrm{~cm}$ na régua limnimétrica.

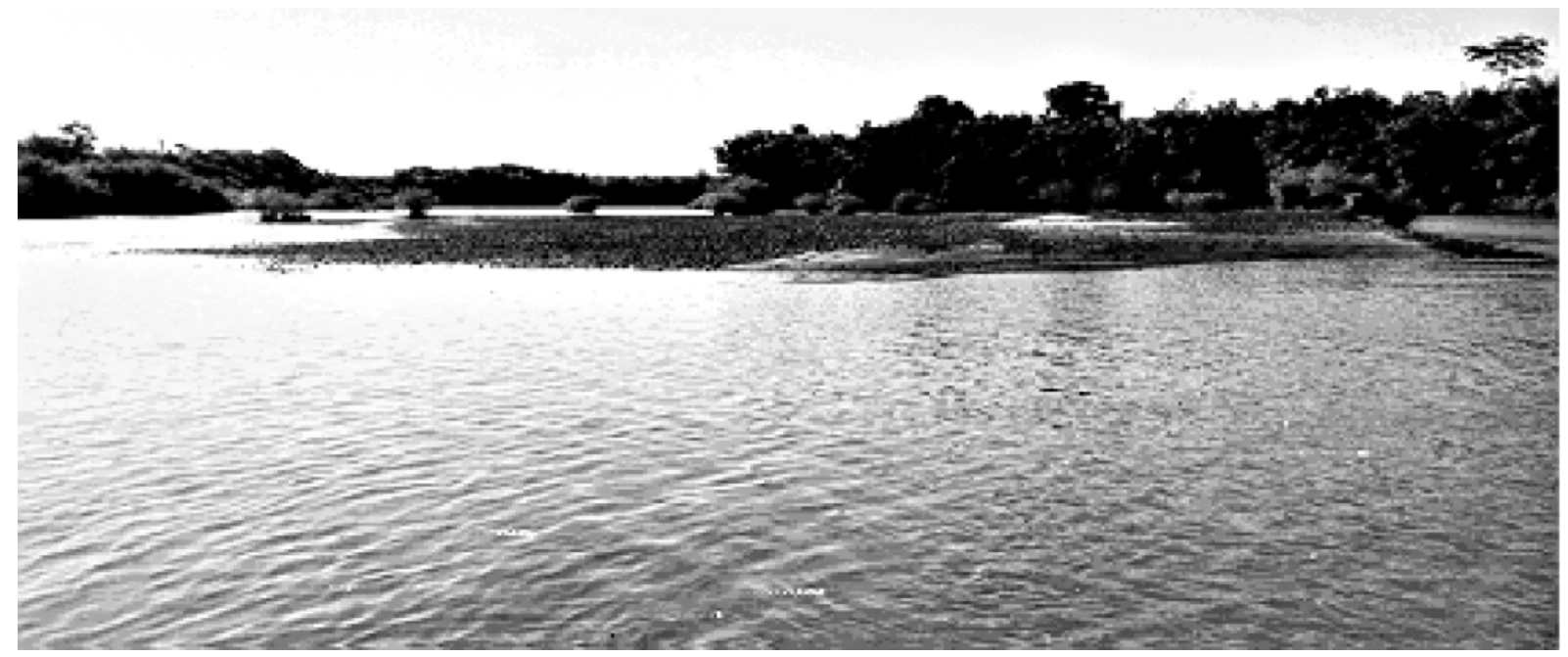

Figura 9 - Mostra uma ilha constituída de seixos em Três Ilhas (Tapira-PR). Os seixos de até 20cm de eixo maior formam um depósito mal selecionado, recoberto com areia média e uma fina camada de argila. A vegetação estabiliza essa barra de canal, fixando-a e permitindo sua acresção vertical nos períodos de cheias

\section{Considerações finais}

A planície aluvial do rio Ivaí mostra por intermédio de suas diferentes unidades morfoestratigráficas e referentes associações faciológicas a complexa evolução da arquitetura aluvial. Escavada sobre as litologias da Formação Caiuá, teve sua evolução associada a estruturação da bacia hidrográfica do rio Paraná, provavelmente já a partir do Terciário. O múltiplo retrabalhamento das unidades morfoestratigráficas, com a formação de nítidas superfícies erosivas e o isolamento de terraços são resultado da interação de eventos climáticos e tectônicos que atuaram ao longo de todo o seu desenvolvimento. A tectônica está muito evidenciada pelas mudanças abruptas na direção geral do rio Ivaí e de seus meandros. A largura e a espessura dos depósitos dentro dos paleocanais mais antigos mostram que o sistema sempre foi muito encaixado, revelando atuação da tectônica.

O controle climático está demonstrado na associação vertical da fácies. Na base da seqüência, a ocorrência de cascalhos maciços altamente limonitizados sugere sua formação a partir de regimes torrenciais sob os climas secos do Pleistoceno. A perda de energia do sistema está revelada pelo afinamento do tamanho das partículas para o topo dos depósitos, com a grande deposição de pelitos, que indica a ocorrência de climas mais úmidos a parir do início do Holoceno. 
O rio, devido ao seu forte encaixamento, faz com que a planície, nos setores médio e superior, se comporte como terraços. $\mathrm{O}$ ativo trabalho vertical do canal gera superposição de depósitos recentes sobre os mais antigos, dificultando a sua separação.

\section{Agradecimentos}

À Fundação Araucária, pelo financiamento da pesquisa "Regime hidrológico do rio Ivaí em seu curso inferior: ênfase à análise geoambiental”, que possibilitou tanto a aquisição de equipamentos quanto o financiamento dos trabalhos de campo, dos quais decorre este trabalho.

\section{Referências Bibliográficas}

AGUIAR, A. M. \& SANTOS, M.L. (2004) Implantação de um banco de dados georreferenciados no curso inferior do rio Ivaí. In: XIII Encontro Anual de Iniciação Científica, Londrina. Anais do... Londrina, CD ROM, 1p.

ALLEN, J.R.L. (1983) Studies in Fluviatile sedimentation: bars, bars-complexes and sandstones sheets (low sinuosity braided streams) in the Brownstones L. Devonian Welsh Borders. Sedimentology Geology, 33: 237-293.

ANDRADE, A.R. (2002) Variabilidade da precipitação pluviométrica da bacia hidrográfica do rio Ivaí$P R$. Dissertação de Mestrado em Geografia, Universidade Estadual de Maringá, (inédito), 99p.

AMARAL, G. \& Costa, A.P. (1983) Comportamento estrutural e estratigráfico dos diferenciados ácidos da Formação Serra Geral na porção sul da bacia do Paraná. In: Simpósio Regional de Geologia, 4, São Paulo. Atas do .... São Paulo, p. 197-210.

ASMUZ, H.E. (1981) Relacionamento genético de feições geológicas da margem continental sudeste e da área continental emersa adjacente. In: Simpósio Regional de Geologia, 3, Curitiba. Atas do... Curitiba, 1: 262-273.

BARROS, C. S. (2006) Dinâmica sedimentar e hidrológica na confluência do rio Ivaí com o rio Paraná, município de Icaraíma - Pr. Maringá, Dissertação de Mestrado em Geografia, Departamento de Geografia, Universidade Estadual de Maringá (inédito), 53p.

BIAZIN, P. C. (2005) Característica Sedimentar e Hidrológica do rio Ivaí em sua foz com o rio Paraná, Icaraíma-Pr. Dissertação de Mestrado em Geografia, Departamento de Geografia, Universidade Estadual de Maringá (inédito), 80p.
BRIERLEY, G.J. (1991) Bar sedimentology of the Squamish River. Bristish Columbia: definition and aplication of morphostratigraphic units. Journal of Sedimentary Petrology, 61 (2): 211-225.

COPEL-Companhia Paranaense de Energia (1984) Diagnóstico do aproveitamento do baixo curso do rio Ivaí para transporte e geração de energia. Governo do estado do Paraná. Relatório Interno, 2v., 401p.

DESTEFANI, E. V. (2005) Regime hidrológico do rio Ivaí. Dissertação de Mestrado em Geografia Departamento de Geografia, Universidade Estadual de Maringá (inédito), 93p.

ETHRIDGE, F.G.; Flores, R.M. \& Harvey, M.D. (eds) (1987) Recents developments in Fluvial Sedimentology, SPEC. Publs. Soc. Econ. Palentol.. Miner. 39, 389 p.

FERNANDES, L. A. (1992) A cobertura cretácea suprabasáltica no Paraná e Pontal do Paranapanema (SP.): os Grupos Bauru e Caiuá. Dissertação de Mestrado, Instituto de Geociências da Universidade de São Paulo, (inédito), 129p.

FERREIRA, F.J.F. (1982) Integração de dados aeromagnéticos e geológicos: configuração $e$ evolução tectônica do arco de Ponta Grossa. Dissertação de Mestrado, Instituto de Geociências da Universidade de São Paulo, (inédito), 169p.

FORTES, E.; STEVAUX, J.C. \& VOLKMER, S. (2005) Neotctonics and channel evolution of the lower Ivinhema river: a right-bank tributary of the upper Paraná river, Brazil. Geomorphology 70:325-338.

FRIEND, P.F. (1983) Towards the field classification of alluvial architeture or sequence. In: COLLINSON, J.D. \& LEWIN, J., (eds), Modern and Ancient Fluvial Systems. Int. Assoc. Sediment. Spec. Publ.,6: 345-354.

FÚLFARO, V.J. (1974) Tectônica do alinhamento estrutural do Paranapanema. Boletim do Instituto de Geologia, USP, 5: 129-138.

FÚLFARO, V.J.; ANGELI, N. \& BARCELOS, J.H. (1982) Depósitos de bacia hidrográfica do rio Paraná. In: Simp. Reg. Geol., 4, SBG São Paulo. Bol. Res. do ... São Paulo, p.25.

FÚLFARO, V.J. \& BARCELOS, J,H. (1992) A tectônica pósdeposicional e a reconstituição paleogeográfica: o exemplo no Grupo Bauru. In: Simpósio Bacias Cretáceas Brasileiras, 2, Rio Claro. Resumos Expandidos do... Rio Claro, p. 132-133. 
JABUR, I.C. (1992) Análise paleoambiental do Quartenário Superior na bacia do Alto Paraná. Tese de Doutorado, Instituto de Geociências e Exatas, Universidade Estadual Paulista, Rio Claro, (inédito), 184p.

JUSTUS, J. O. (1985) Subsídios para a interpretação morfogenética através da utilização de imagem de radar. Dissertação de Mestrado, Universidade Federal da Bahia, Salvador, (inédito), 204p.

KUERTEN, S. (2006) Variação longitudinal das características sedimentares e hidrológicas do rio Ivaí-Pr em seu curso inferior. Dissertação de Mestrado em Geografia, Departamento de Geografia, Universidade Estadual de Maringá (inédito), 73p.

MIALL, A.D. (1978) Lithofacies types and vertical profile models in braided river deposits; A summary. Fluvial Sedimentology. A.D. MIALL (Ed.). Canadian Soc. of Petrol Geol. Memoir 5, p. 597-604.

MIALL, A.D. (1992) Alluvial deposits. In : Walker, R.G. e JAMES, n. P. (eds.) Facies Models Response to Sea Level change. Geol. Assoc. of Canada. 409. p.

MOLINA, E.C.; USSAMI, N.; SÁ, N.C. \& BLITZKOW, D. (1989) Interpretração dos dados gravimétricos da parte norte da bacia do Paraná. Revistas Brasileiras de Geociências, 19 (2): 187-196.

MUÑOZ, A.; RAMOS, A.; SANCHES-HOYA, Y. \& SOPÑA A. (1992) Evoluing fluvial architecture during a marine transgression : upper Buntsandtein, Triassic, centry Spain. Sedimentary Geology, 75: 257-281

RAMOS, F. (1973) Vazões de estiagem em pequenas bacias hidrográficas do estado do Paraná. CEPHH. Curitiba, UFPR.

SAAD, A. R.; CAMPANHA, V.A.; CABRAL, J. R.; ETCHEBEHERE, M. L. C.; FOLHO, P.P.; MOTTA, J. F. M. \& SILVA, F. P. (1988) Cenários do Grupo Bauru (K) no estado de São Paulo. in: Cong. Bras. de Geol., 35, Belém. Anais do... Belém SBG. 2:894-904.

SANTOS, I. (1999) Avaliação por perdas de solo por erosão hídrica na bacia do rio Ivaí. XIII Simpósio Brasileiro de Recursos Hídricos, Anais do...., Belo Horizonte, CD ROM, 13p.
SANTOS, M.L. (2004) Relatório técnico final, Projeto rio Ivaí. Relatório interno da Fundação Araucária PR. 185p.

SANTOS, M. L. (1997) Estratigrafia e evolução do sistema siliciclástico do rio Paraná no seu curso superior: ênfase à arquitetura dos depósitos, variação longitudinal das fácies e processos sedimentares. Tese de Doutoramento em Geociências, Instituto de Geociências, Universidade Federal do Rio Grande do Sul, (inédito), 2v., 246p.

SOARES, P.C.; BARCELOS, P.E.; CORDAS, S.M.; MATTOS, J.T.; BALIEIRO, M.G. e MENEZES, P.R. (1982) Lineamentos em imagens Landsat e de radar e suas implicações no conhecimento tectônico da bacia do Paraná. In: Simpósio Brasileiro de Sensoreamento Remoto, 2, Brasília. Anais do..., Brasília, 1: 143-156.

SOUZA FILHO, E.E. (1993) Aspectos da geologia e estratigrafia dos depósitos sedimentares do rio Paraná entre Porto Primavera (MS) e Guaíra $(P R)$. Tese de Doutorado, instituto de Geociências da Universidade de São Paulo, (inédito), 214p.

SOUZA FILHO, E.E. \& STEVAUX, J. C. (1997) Geologia e geomorfologia do complexo rio Baía, Curutuba, Ivinheima. In: Vazzoler, A. E. A. de M.; Agostinho, A.A.; Hahn, N. S. (eds.). A Planície de Inundação do Alto rio Paraná, EDUEM, Maringá, 3-47.

STEVAUX, J. C. (1993) O Paraná: geomorfogênese, sedimentação e evoluçãp quaternária do seu curso superior (região de porto rico, PR). Tese de Doutorado, Instituto de Geociências da Universidade de São Paulo, (inédito), 242p.

STEVAUX, J. C. (1994) The upper Parana river (Brazil): Geomorphology, sedimentology and paleoclimatology. Quaternary International, 21:143-161.

STEVAUX, J.C. \& SANTOS, M.L. (1998) Palaeohydrological changes in the upper Parana river, Brazil, during the late Quaternary: A facies approach. In: BENITO, G., BAKER,V.R. and GREGORY, K.J. (eds.). Palaeohydrology and environmental change. John Wiley \& Sons, London, 273-288.

ZALAN, P.V.; WOLFF, S; CONCEIÇÃO, J.C.J.; MARQUES, A.; ASTOLFI, M.A.M.; VIEIRA, I.S.; APPI, V.I. \& ZANOTTO, O.A. (1991) Bacia do Paraná in: GABAGLIA, G.P.R. \& MILANI, E. J. Origem e evolução de bacias sedimentares. Petrobrás, Rio de Janeiro, 135-168. 